\title{
Hereditary hypophosphatemia in Norway: a retrospective population-based study of genotypes, phenotypes, and treatment complications
}

\author{
Silje Rafaelsen ${ }^{1}$, Stefan Johansson ${ }^{1,2}$, Helge Ræder ${ }^{1,3}$ and Robert Bjerknes ${ }^{1,3}$ \\ ${ }^{1}$ Section for Pediatrics, Department of Clinical Science, Haukeland University Hospital, University of Bergen, N-5021 \\ Bergen, Norway, ${ }^{2}$ Center for Medical Genetics and Molecular Medicine and ${ }^{3}$ Department of Pediatrics, Haukeland \\ University Hospital, Bergen, Norway
}

Correspondence should be addressed to S Rafaelsen

Email

Silje.Rafaelsen@uib.no

\begin{abstract}
Objective: Hereditary hypophosphatemias $(\mathrm{HH})$ are rare monogenic conditions characterized by decreased renal tubular phosphate reabsorption. The aim of this study was to explore the prevalence, genotypes, phenotypic spectrum, treatment response, and complications of treatment in the Norwegian population of children with $\mathrm{HH}$.

Design: Retrospective national cohort study.

Methods: Sanger sequencing and multiplex ligand-dependent probe amplification analysis of $P H E X$ and Sanger sequencing of FGF23, DMP1, ENPP1KL, and FAM2OC were performed to assess genotype in patients with $\mathrm{HH}$ with or without rickets in all pediatric hospital departments across Norway. Patients with hypercalcuria were screened for SLC34A3 mutations. In one family, exome sequencing was performed. Information from the patients' medical records was collected for the evaluation of phenotype.

Results: Twety-eight patients with HH (18 females and ten males) from 19 different families were identified. X-linked dominant hypophosphatemic rickets (XLHR) was confirmed in 21 children from 13 families. The total number of inhabitants in Norway aged 18 or below by 1st January 2010 was 1 109 156, giving an XLHR prevalence of $\sim 1$ in 60000 Norwegian children. FAM2OC mutations were found in two brothers and SLC34A3 mutations in one patient. In XLHR, growth was compromised in spite of treatment with oral phosphate and active vitamin $D$ compounds, with males tending to be more affected than females. Nephrocalcinosis tended to be slightly more common in patients starting treatment before 1 year of age, and was associated with higher average treatment doses of phosphate. However, none of these differences reached statistical significance.

Conclusions: We present the first national cohort of HH in children. The prevalence of XLHR seems to be lower in Norwegian children than reported earlier.
\end{abstract}

\section{Introduction}

Hereditary hypophosphatemia $(\mathrm{HH})$ is a group of rare diseases with disordered phosphate metabolism and decreased renal tubular phosphate reabsorption (1). In hypophosphatemic rickets (HR), the hypophosphatemia is associated with rickets and osteomalacia, whereas syndromes with hypophosphatemia combined with osteosclerosis and ectopic calcifications, and not rickets or osteomalacia, are also recognized (1).

HR can be classified as either dependent or independent of the bone derived fibroblast growth factor 23 (FGF23) (1). FGF23 is a phosphate-regulating hormone (2), acting on kidney tubuli cells to decrease expression of
(C) 2016 The authors Published by Bioscientifica Ltd.

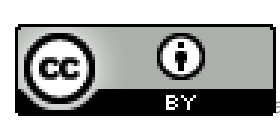

This work is licensed under a Creative Commons Attribution 3.0 Unported License. 
sodium-phosphate co-transporter types IIa and IIc (NaPiIIa and NaPi-IIc) encoded by SLC34A1 and SLC $34 A 3$ respectively. Elevated levels of serum phosphate increase the expression of FGF23 thereby decreasing the reabsorption of phosphate in the renal proximal tubule, while hypophosphatemia normally down regulates the expression of FGF23. FGF23 also down regulates the1- $\alpha$ hydroxylase (encoded by CYP27b1), thus inhibiting the activation of $25 \mathrm{OH}$ vitamin D (25OHD) to $1,25(\mathrm{OH})_{2}$ vitamin $\mathrm{D}\left(1,25(\mathrm{OH})_{2} \mathrm{D}\right)$, and up regulates 24-hydroxylase (encoded by CYP24a1), which inactivates $1,25(\mathrm{OH})_{2} \mathrm{D}$ by conversion to $24,25(\mathrm{OH})_{2}$ vitamin D (3). In FGF23dependent $\mathrm{HR}$, the physiological increase in serum $1,25(\mathrm{OH})_{2} \mathrm{D}$ in response to hypophosphatemia is blunted, and the result is a serum level of $1,25(\mathrm{OH})_{2} \mathrm{D}$ that is low, or inappropriately normal for the degree of hypophosphatemia (4).

FGF23 dependent HR is caused by mutations in genes involved in the FGF23 bone-kidney-axis, with levels of intact FGF23 (iFGF23) being elevated or inappropriately normal in the setting of hypophosphatemia when suppressed FGF23 is to be expected (1). FGF23 dependent HR includes X-linked dominant HR (XLHR) caused by lossof-function mutations in the phosphate regulating endopeptidase homolog, X-linked (PHEX) gene (5), autosomal dominant HR caused by gain of function mutations in the FGF23 gene (6), and three types of autosomal recessive HR. ARHR1 is caused by mutations in the DMP1 gene, encoding the dentin matrix protein $1(7,8)$, ARHR2 is caused by mutations in the ENPP1 gene encoding the ectonucleotide pyrophosphatase/phosphodiesterase 1 $(9,10)$, whereas we have recently shown an association between biallelic mutations in FAM20C and FGF23dependent ARHR3 in a Norwegian family (11). FAM20C encodes a protein kinase, important in many phosphorylation processes. Phosphorylation of FGF23 by FAM20C makes FGF23 less stable by inhibiting $O$-glycosylation by GalNacT3 (12), and inactivating mutations in FAM20C thus leads to increased levels of iFGF23 $(11,13)$. There is also one report of FGF23 dependent HR caused by an activating translocation leading to up-regulation of the expression of the KL gene, encoding the anti-aging protein $\alpha$-klotho (14). In FGF23-independent HR, as seen in hereditary HR with hypercalcuria (HHRH) caused by mutations in the SLC34A3 gene $(15,16)$, the level of iFGF23 is appropriately down-regulated (16).

Treatment of HR includes oral phosphate replacement several times daily, combined with calcitriol to counteract the secondary hyperparathyroidism (HPT) elicited by the serum phosphate peak (17) and transient decrease in serum ionized calcium upon phosphate dosing. Treatment is balanced to improve linear growth and reduce skeletal deformities while simultaneously minimizing the risk of complications to treatment such as secondary and tertiary HPT, nephrocalcinosis, hypertension, and renal failure (18).

We have conducted the first complete national study of $\mathrm{HH}$ in children, to explore the prevalence, genotypes, phenotypic spectrum, and response to and complications of treatment.

\section{Subjects and methods}

\section{Patient population}

During 2009 all pediatric hospital departments in Norway were contacted to identify children with $\mathrm{HH}$. The number of patients identified was compared to the number of patients younger than 18 years registered in the Norwegian Patient Registry (NPR) with the diagnosis code 'E83.3 Disorders of phosphorus metabolism and phosphatases' in the World Health Organization's International Classification of Diseases version 10 (WHO ICD-10). Patients were continuously recruited through the years 2009-2014.

The inclusion criteria for $\mathrm{HH}$ were serum phosphate below the age dependent reference range in repeated samples combined with tubular maximum reabsorption rate of phosphate per glomerular filtration rate (TmP/GFR) not due to primary HPT, HPT secondary to renal failure or malabsorption, Fanconi syndrome or other tubulopathy, vitamin $\mathrm{D}$ dependent rickets, vitamin $\mathrm{D}$ deficiency or hypophosphatemia secondary to acute metabolic derangements. A family history or genetic diagnosis was supportive, but not required for inclusion.

\section{Genetic analysis}

Genomic DNA was purified from blood using the QiaSymphony System (Qiagen). If the mutation status was not already known, all exons and intron-exon boundaries of PHEX were sequenced in the index case of each family. If a disease causing mutation was not found, and the inheritance pattern suggested a sporadic case or $\mathrm{X}$-linked dominant disease, multiplex ligand-dependent probe amplification (MLPA) analysis of PHEX were performed at the Molecular Genetics Laboratory, Royal Devon and Exeter Foundation NHS Trust, Exeter, Devon, UK. The PHEX MLPA analysis can identify mid-size deletions and insertions not detected by regular Sanger sequencing or chromosomal analysis. 
All exons and intron-exon boundaries of FGF23, DMP1, ENPP1, KL, and FAM20C were sequenced, in successive order, in subjects without pathogenic PHEX mutations.

In short, DNA targets were first amplified by PCR (list of primers available upon request) using the AmpliTaq Gold DNA Polymerase System (Applied Biosystems). PCR amplicons were purified with $2 \mu \mathrm{l}$ of ExoSapIT. Using the Big Dye Terminator chemistry sequencing was performed on the 3730 DNA analyzer (Applied Biosystems) and analyzed using the SeqScape Software (Applied Biosystems).

All mutations detected were compared to variants previously reported in the SNP database (http://www.ncbi. nlm.nih.gov/projects/SNP/index.html) and in the PHEX database (http://www.pahdb.mcgill.ca/cgi-bin/phexdb/ phexdb_mutQ1.cgi?field=ID_mut\&value=).

\section{Review of medical history}

Information on age at diagnosis, clinical and biochemical findings at diagnosis, treatment, and complications was collected by review of the medical records of included patients. Height was converted to $z$-scores according to Norwegian growth charts (19). Delta $z$-score was calculated as the difference between $Z$-score at last registered consultation and $z$-score at diagnosis. Laboratory data from each visit from the time of diagnosis to the time of inclusion in the study, including serum levels of calcium, phosphate, alkaline phosphatase, creatinine, parathyroid hormone $(\mathrm{PTH}), 25 \mathrm{OHD}$, and $1,25(\mathrm{OH})_{2} \mathrm{D}$ were also recorded, as well as results from kidney ultrasound and skeletal X-ray examinations. TmP/GFR was calculated according to the formula provided by Barth et al. (20). Blood tests were analyzed according to each hospital laboratory's current standard methods.

\section{Genotype-phenotype associations in XLHR patients}

The PHEX mutations were classified as either deleterious or plausible according to earlier studies (21). Deleterious mutations comprise those leading to a premature stop codon, including nonsense mutations, splice-site mutations, and insertions and deletions affecting reading frame. Mutations classified as plausible were missense mutations and deletions that did not affect reading frame. The phenotypic features compared were age at diagnosis and at the last registered consultation, height $z$-score at diagnosis and at the last registered consultation, serum levels of phosphate, ALP and PTH at diagnosis, skeletal manifestations (clinical or radiological signs of rickets or bowing) at diagnosis, and information on dental involvement, nephrocalcinosis, and persistent bowing at the last registered consultation.

\section{Statistical analysis}

The prevalences of HH and XLHR was calculated based on the number of patients aged 0-18 years registered with these diagnosis in 2009 and the total number of people in Norway aged 0-18 years by 1st January 2010, obtained from the official Statistics Norway database (22).

The data were analyzed with SPSS version 22 . Between-group comparisons were performed using nonparametric tests; medians were compared using the MannWhitney $U$ test, and frequencies were compared with the Fisher's exact test.

\section{Ethics and approvals}

Written informed consent was obtained from all study participants. The study was approved by the Regional Committee for Medical and Health Research Ethics, Region West, Norway (REK number 2009/1140).

Clinical Trial Registration (ClinicalTrials.gov) number: NCT01057186.

\section{Results}

\section{HH patient cohort}

By 31st December 2009 we had identified a total of 23 children aged 0-18 years with $\mathrm{HH}$ in Norway, and all except one were included in this study. Two additional patients with $\mathrm{HH}$, one with confirmed XLHR, were born before 2009, but diagnosed after 2010. By the end of 2009 the National Patient Registry reported 32 children with the ICD-10 diagnosis 'E83.3 Disorders of phosphate metabolism and phosphatases', but four of these patients had hypophosphatasia, and five had transient hypophosphatemia in the course of malignancy, premature birth, or other underlying condition. On 1st January 2010, the number of inhabitants aged below 18 years was 1109 156, and this gives a prevalence of $\mathrm{HH}$ of $\sim 1$ in 45000 children. XLHR was confirmed in 18 children, giving a prevalence of $\sim 1$ in 60000 . During the period from 1st January 2010 to 31st December 2014, we included another four patients, two of which immigrated to Norway in 2014 and two patients born to XLHR mothers after 2010.

The total of 28 patients included comprised 18 females and ten males from 19 different families 
(Supplementary Figure 1, see section on supplementary data given at the end of this article). XLHR was confirmed in 21 children. Twenty-two patients had a family history of HR, while six were sporadic cases.

\section{Genotypes in $\mathrm{HH}$}

We identified the likely pathogenic mutation in 15 of the $19 \mathrm{HH}$ pedigrees (79\%). PHEX mutations were found in 21 subjects from 13 different pedigrees (Supplementary Table 1 , see section on supplementary data given at the end of this article), and three of the XLHR probands were sporadic. Of the 13 different PHEX mutations detected, nine had not been previously reported in the SNP or PHEX databases (see section 'Materials and methods'). The nine novel mutations comprised one large duplication, two single nucleotide deletions leading to frameshift and premature stop codons, two triplet deletions leading to loss of one or more codons, two missense mutations, one nonsense mutation, and one splice site mutation. One male patient with $\mathrm{HHRH}$ was found to be compound heterozygous for a splicing mutation, c.757-1G $>\mathrm{A}$, and an intronic deletion mutation, c.925+20_926-48del, in the SLC34A3 gene. The c.757-1G $>\mathrm{A}$ affects the conserved splice donor site of intron 7 , and is predicted to cause aberrant splicing. The c.925+20_926-48del mutation has been reported previously (15). Two patients with combined heterozygous mutations in FAM20C are described elsewhere (11). In four patients, two sporadic cases in females and two males with affected mothers, we were not able to identify a pathogenic mutation by standard Sanger sequencing of PHEX, FGF23, DMP1, ENPP1 or KL, or by PHEX MLPA.

\section{Phenotypes in $\mathrm{HH}$}

The median age at diagnosis was 2.1 years (range $0.1-15.5$ years), and 26 of the 28 subjects were diagnosed before the age of 7 years (Table 1 and detailed information for each subject is given in Supplementary Table 2, see section on supplementary data given at the end of this article). Median age at the last registered consultation was 12.1 years (range $1.3-18.3$ ).

Phenotype in XLHR - The 21 XLHR children comprised 16 females and five males. Their median age was 0.9 years (range 0.1-15.5) at diagnosis, and 10.8 years (range 1.318.0) at the last registered consultation. Growth was compromised, and Fig. 1 illustrates the height $z$-scores for 19 of the 21 XLHR patients related to age at diagnosis and at the last registered consultation. Males tended to have a lower height $z$-score than females (Table 2), both at diagnosis and at the last registered consultation, whereas delta $z$-score did not differ between the sexes. In accordance with an earlier study (23), we analyzed the XLHR patients' data depending on initiation of treatment before or after 1 year of age. There was no significant improvement in height $z$-score in either treatment group.

Table 1 Characteristics of the cohort of patients with hereditary hypophosphatemia ${ }^{a}$.

\begin{tabular}{l}
\hline \\
\hline Time of diagnosis \\
Sex (male/female) $(n / n)$ \\
Family history of HH $(n / N)$ \\
Age at diagnosis (years) \\
Height ( $z$-score) \\
Skeletal disease ${ }^{\text {b }}(n / N)$ \\
Treatment \\
Age at treatment start (years) \\
Elemental phosphorus (mg/kg per day) \\
Alfacalcidol (ng/kg per day) \\
Last registered consultation \\
Age (years) \\
Height ( $z$-score) \\
Delta $z$-score height $(z$-score) \\
Dental involvement $(n / N)$ \\
Nephrocalcinosis $(n / N)$ \\
Persistent bowing $(n / N)$ \\
\hline
\end{tabular}

\begin{tabular}{c}
\hline All patients $(n=28)$ \\
$10 / 18$ \\
$22 / 28$ \\
$2.1(0.1$ to 15.5$)$ \\
$-0.9(-6.5$ to 1.0$)$ \\
$17 / 28$ \\
$2.1(0.2$ to 15.6$)$ \\
$39(28$ to 61$)$ \\
$33(21$ to 42$)$ \\
$12.1(1.3$ to 18.3$)$ \\
$-1.4(-6.31$ to 0.8$)$ \\
$-0.1(-3.1$ to 2.0$)$ \\
$13 / 28$ \\
$11 / 28$ \\
$16 / 28$
\end{tabular}

XLHR $(n=21)$
$5 / 16$
$18 / 21$
$0.9(0.1$ to 15.5$)$
$-1.2(-6.5$ to 1.0$)$
$13 / 21$
$1(0.2$ to 6.7$)$
$39(0$ to 74$)$
$34(0$ to 54$)$
$10.8(1.3$ to 18.0$)$
$-1.4(-6.3$ to 0.8$)$
$-0.1(-3.1$ to 2.0$)$
$9 / 21$
$9 / 20^{c}$
$13 / 21$

$n / N$, number of patients with this characteristic/total number of patients.

${ }^{a}$ Continual variables are given as median (range).

bSkeletal disease: clinical or radiological signs of rickets, or skeletal axis deviation.

Information missing for one patient. 


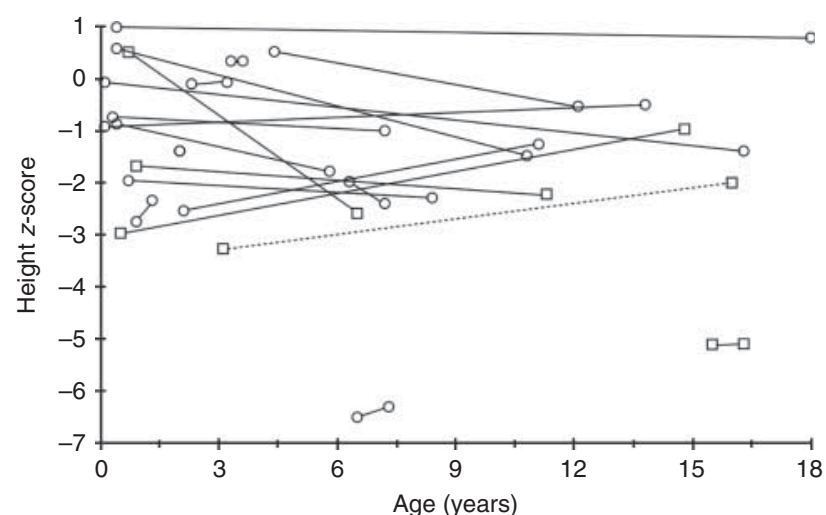

Figure 1

Growth in X-linked hypophosphatemic rickets. Ages at diagnosis and last registered consultation, and the corresponding height $z$-scores for 19 of the 21 XLHR patients. The two outliers represent two immigrant siblings who had not received any medical care and did not start treatment until age 6 and 15 years respectively. The broken line represents the male treated with growth hormone. Circles represent females and squares represent males.

One patient was treated with growth hormone (GH) from the age of 11 years 10 months. His height $z$-score improved from -2.9 at the last consultation before initiation of $\mathrm{GH}$ to a final height of -1.9 s.D. at age 17 years (data not shown).

Clinical or radiological evidence of skeletal involvement was found in 13 of 20 children (four out of five males and nine out of 15 females) at diagnosis. The seven patients without skeletal manifestations at diagnosis were all familial cases, diagnosed before the age of 8 months (median 4 months), and comprised six females and one male. During the years after diagnosis, all of these had episodes of rickets identified on clinical or radiological examination, and a male and two of the females had persisting skeletal axis deviations at the last registered consultation. Overall, nine females and four males had persisting axis deviation at the last registered consultation, and correcting osteotomy had been performed in one female and two males. The prevalence of dental involvement was higher in male than female XLHR patients, and in children who started treatment after the age of 1 year (Table 2 ).

Genotype-phenotype associations in XLHR There were no differences between the mutation status groups in growth, dental involvement, persistent bowing, or development of nephrocalcinosis (results not shown).

\section{Treatment and complications in $\mathrm{HH}$}

The median age at the start of treatment was 2.1 years. Twenty-six of the 28 patients were treated with oral phosphate and vitamin D (alfacalcidol) supplements (Table 1). Two patients were diagnosed at the time of inclusion, and had not started any treatment at that point.

Treatment and complications in XLHR $~$ Details of medical treatment were available for 19 of the 21 XLHR

Table 2 Effect of gender and early start of treatment in X-linked hypophosphatemic rickets ${ }^{a}$.

\begin{tabular}{|c|c|c|c|c|}
\hline & \multicolumn{2}{|c|}{ Stratified by gender } & \multicolumn{2}{|c|}{ Age at treatment start } \\
\hline & Male $(n=5)$ & Female $(n=16)$ & $<1$ year $(n=10)$ & $>1$ year $(n=9)$ \\
\hline \multicolumn{5}{|l|}{ Time of diagnosis } \\
\hline Age (years) & $0.9(0.5$ to 15.5$)$ & $1.5(0.1$ to 6.5$)$ & $0.4(0.1$ to 0.9$)$ & $3.3(0.7$ to 15.5$)$ \\
\hline Height (z-score) & $-3(-5.1$ to 0.5$)$ & $-0.9(-6.5$ to 1.0$)$ & $-0.8(-3.0$ to 1.0$)$ & $-2(-6.5$ to 0.5$)$ \\
\hline Skeletal disease $^{\mathrm{b}}(n / N)$ & $4 / 5$ & $9 / 15$ & $3 / 10$ & $9 / 9$ \\
\hline \multicolumn{5}{|l|}{ Treatment data } \\
\hline Age at treatment start (years) & $1(0.5$ to 3.6$)$ & $1.1(0.2$ to 6.7$)$ & $0.6(0.2$ to 1.0$)$ & $3.6(1.2$ to 15.6$)$ \\
\hline Elemental phosphorus (mg/kg per day) & 50 (32 to 64$)$ & $32(0$ to 74$)$ & 59 (11 to 74$)$ & 35 (28 to 67$)$ \\
\hline Alfacalcidol (ng/kg per day) & 49 (37 to 54$)$ & $28(0$ to 48$)$ & $42(17$ to 54$)$ & 26 (17 to 37$)$ \\
\hline \multicolumn{5}{|l|}{ Last registered consultation } \\
\hline Age (years) & $14.8(6.5$ to 16.3$)$ & $7.9(1.3$ to 18.0$)$ & $11.1(1.3$ to 18.0$)$ & $8.4(3.2$ to 16.3$)$ \\
\hline Height (z-score) & $-2.2(-5.1$ to -1.0$)$ & $-1.4(-6.3$ to 0.8$)$ & $-1.4(-2.6$ to 0.8$)$ & $-2(-6.3$ to 0.3$)$ \\
\hline Delta $z$-score (z-score) & $0(-2.1$ to 1.3$)$ & $-0.2(-3.1$ to 2.0$)$ & $-0.4(-3.1$ to 2.0$)$ & $0(-1.1$ to 1.3$)$ \\
\hline Dental involvement $(n / N)$ & $4 / 5$ & $5 / 15$ & $2 / 10$ & $7 / 9$ \\
\hline Nephrocalcinosis $(n / N)$ & $2 / 5$ & $7 / 15$ & $7 / 10$ & $2 / 9$ \\
\hline Persistent bowing $(n / N)$ & $4 / 5$ & $9 / 15$ & $5 / 10$ & $7 / 9$ \\
\hline
\end{tabular}


patients. In this group, the median age at the start of treatment with oral phosphate and alfacalcidol was 1.0 year (range 0.2-15.6), and ten of 19 children started treatment before the age of 1 year.

Information concerning development of nephrocalcinosis was available for 20 of 21 XLHR patients, and nephrocalcinosis was diagnosed in nine of 20 (45\%), at a median age 4 years 6 months (range 1 year-5 years 5 months), after a median time in treatment of 1 year 5 months (range 8 months -4 years 5 months). The median time in treatment for patients without registered nephrocalcinosis was 7 years 2 months (range 0-14 years 7 months).

All nine XLHR patients who developed nephrocalcinosis did so within 5 years of treatment. Of the 11 patients without nephrocalcinosis, only four had been treated for 5 years or more, and were included in further comparisons. The prevalence of nephrocalcinosis in this subgroup was nine of 13 (69\%). There was a trend toward a higher average daily dose of phosphate (given as $\mathrm{mg} / \mathrm{kg}$ per day elemental phosphorus) during the years before the diagnosis of nephrocalcinosis as compared to the daily phosphate dose during the first 5 treatment years in patients without nephrocalcinosis (Fig. 2A) (median $61.0 \mathrm{mg} / \mathrm{kg}$ per day (range 12.1-79.0) and median $44.8 \mathrm{mg} / \mathrm{kg}$ per day (range 13.8-64.7) respectively). Moreover, there was a tendency for earlier start of treatment in children who developed nephrocalcinosis compared with children that did not (median 0.5 year vs 1 year; range $0.2-4.4$ vs $0.6-3.6$ ), and seven of nine children with nephrocalcinosis and two of four children without
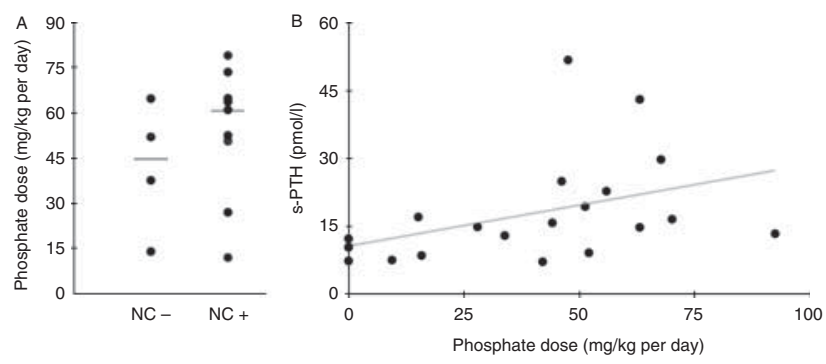

\section{Figure 2}

Complications in X-linked hypophosphatemic rickets.

(A) Nephrocalcinosis: the average daily phosphate (given as $\mathrm{mg} / \mathrm{kg}$ per day elemental phosphorus) dose in patients who developed nephrocalcinosis (NC+) and patients who did not $(\mathrm{NC}-$ ). The horizontal lines represent the median in each group. (B) Hyperparathyroidism: the relationship between the maximum registered value of serum PTH and phosphate dose (given as $\mathrm{mg} / \mathrm{kg}$ per day elemental phosphorus) at the same time point. nephrocalcinosis had started treatment before 1 year of age. There were no differences in the starting doses of phosphate and alfacalcidol, average daily dose of alfacalcidol, serum level of PTH level at diagnosis, maximum registered serum $\mathrm{PTH}$, or maximum registered urinecalcium/creatinine ratio (U-Ca/creatinine; results not shown). Furthermore, the groups did not differ with respect to the occurrence of skeletal symptoms at diagnosis, dental involvement at diagnosis, persistent bowing at the last registered consultation, or delta height $z$-score (not shown).

Information concerning parathyroid state was available in 18 patients, of whom 16 had elevated levels of total intact PTH at the time of diagnosis (Table 1 and Supplementary Table 2a). All patients developed transient HPT during treatment in the face of normocalcemia. As seen in Fig. 2B, there was a positive association between the maximum measured serum PTH and the daily dose of phosphate (given as $\mathrm{mg} / \mathrm{kg}$ per day of elemental phosphorus). Tertiary HPT was diagnosed in one female XLHR patient at 13 years of age. She had been treated with phosphate and alfacalcidol from the age of 5 months, and during the 12.5 years of treatment, the average phosphate dose was $83.0 \mathrm{mg} / \mathrm{kg}$ per day (range $47.0-127.0 \mathrm{mg} / \mathrm{kg}$ per day) and alfacalcidol dose $18.5 \mathrm{ng} / \mathrm{kg}$ per day (range 11.4-44.0 ng/kg per day). Treatment with calcimimetics was started, and she has avoided the need of parathyroidectomy (24).

Treatment and complications in non-X-linked HH - Nephrocalcinosis was diagnosed in one female patient with no detected mutation in any of the known genes at age 8 years 2 months after 6 years 4 months of treatment with phosphate and alfacalcidol. Nephrocalcinosis was also demonstrated in the male patient with HHRH, before start of treatment. Tertiary HPT was found in one female patient with no established mutations in any of the known genes. She had been treated for 14 years, with an average dose of elemental phosphorus of $45.9 \mathrm{mg} / \mathrm{kg}$ per day (range $38-80 \mathrm{mg} / \mathrm{kg}$ per day) and alfacalcidol $34.2 \mathrm{ng} / \mathrm{kg}$ per day (range $22-49.6 \mathrm{ng} / \mathrm{kg}$ per day) the last 7 years before the development of permanently elevated PTH combined with hypercalcemia. The patient has responded well to treatment with a calcimimetic, and has so far not needed parathyroidectomy.

\section{Discussion}

We have presented the first national cohort of $\mathrm{HH}$ and XLHR in children, describing the prevalence, genotypes, 
phenotypic spectrum, and response to and complications of treatment in the Norwegian pediatric population. The prevalence of XLHR in Norwegian children was one in 60 000. Earlier reports from regional cohorts, with a risk of selection bias, have found the prevalence of XLHR to be $\sim 1$ in $20000(25,26)$. Studies of large pedigrees of XLHR patients have reported a low penetrance of skeletal manifestations in hypophosphatemic female family members, whereas all hypophosphatemic males had skeletal manifestations of disease (27). Hence, there is a possibility of undiagnosed XLHR in Norwegian females from pedigrees without affected males. However, the ratio of female to male patients in our cohort was $16: 5$, as compared to the expected ratio of 2:1 for X-linked dominant disorders; a large proportion of undiagnosed females thus seems unlikely. Since our study included only children already in contact with health care and asymptomatic members of the pedigrees were not tested for hypophosphatemia, we cannot rule out hypophosphatemic second-degree relatives (28). It is therefore possible that the prevalence of $\mathrm{HH}$ and XLHR in the Norwegian pediatric population may be higher than one in 45000 and one in 60000 respectively.

We identified the genotype responsible for $\mathrm{HH}$ in $79 \%$ of pedigrees in this population-based cohort, and PHEX mutations comprised $87 \%$ of the verified mutations. This supports what has been found by others (29), and confirms that XLHR is the most common variant of HR. Of 13 PHEX mutations, nine (69\%) had not been reported earlier (ExAC Browser accessed 21.05.15, http://exac.broadinstitute.org/gene/ENSG00000102174), demonstrating that most mutations are private in this gene (28). We have previously reported two male siblings with the first identified association between compound heterozygous mutations in FAM2OC and FGF23 dependent hypophosphatemia in humans (11). None of the patients had mutations in FGF23, DMP1, ENPP1, or KL, confirming that mutations in these genes rarely seem to be the cause of HH. In four patients we did not find the likely disease causing mutation. However, as illustrated by our finding of FAM20C mutations (11), there are possibilities of mutations in other genes associated with pathways involving FGF23, phosphate reabsorption, and tissue mineralization.

One adolescent male was compound heterozygous for mutations in the SLC34A3 gene. He had no manifestations of rickets, normal growth and bone mineral density, and came to medical attention because of recurrent kidney stones, accompanied by hypercalcuria, hypophosphatemia, suppressed $\mathrm{PTH}$, and high $1,25(\mathrm{OH})_{2} \mathrm{D}$. He had a novel splicing mutation c.757-1G $>$ A affecting the conserved splice donor site of intron 7 , predicted to cause aberrant splicing, and a previously reported intronic deletion mutation, c.925+20_926-48del (15). Earlier studies have shown that about $10 \%$ of homozygous and $16 \%$ of compound heterozygous carriers of mutations in SLC34A3 presented with renal calcifications, without evidence of skeletal involvement $(30,31)$. Thus, our case is consistent with a phenotypic and genotypic heterogenesity in SLC34A3 related conditions, including HHRH.

When comparing non-sense PHEX mutations with missense PHEX mutations likely to reduce protein function, we did not find differences in growth, severity of skeletal or dental disease, or in the prevalence of treatment complications based on the type of mutation. Our findings confirm the results of another recent study (21), whereas other studies have suggested an association between truncating mutations and a more severe skeletal phenotype $(32,33,34)$. However, even in subjects with the same genotype, the skeletal phenotype seems to be very variable and individual $(35,36)$. This might reflect influence from other genetic variants in mineralization and phosphate metabolism. Interestingly, it was recently reported that patients homozygous or heterozygous for the FGF23 sequence variant c.C716T (p.T239M, rs7955866) had significantly lower levels of serum phosphate and lower renal TmP/GFR than patients homozygous for the WT allele (37). Another research group have reported a weak, but significant association between the c.C716T variant of FGF23 and lower $\mathrm{TmP} / \mathrm{GFR}$ and lower plasma intact PTH in healthy children and adults (38). In none of the studies, it was possible to show significantly higher levels of serum iFGF23 in subjects carrying the c.C716T variant.

Evaluation of phenotype in XLHR showed that growth was compromised, and there was a tendency for lower height $z$-scores in males than females. Also, we found a trend for males having a higher proportion of skeletal and dental manifestations than females. As discussed above, some studies points to a milder phenotype in females, with slight hypophosphatemia and mild or no overt skeletal disease $(39,40)$. There are also reports of slightly lower serum levels of phosphate $(40,41)$ and more severe skeletal disease in male than female XLHR patients (42). Other studies have reported no gender differences in skeletal phenotype $(35,43)$, but more severe dental phenotype in post pubertal males than females $(35,44)$. Thus, our findings support the notion of a more severe mineralization defect in males than females. 
Dental involvement seemed to be less common in the patients who started treatment before 1 year of age, suggesting the importance of proper mineralization of dentin prior to the eruption of teeth (45). On the other hand, starting treatment before age 1 year did not lead to an improved height $z$-score at the last registered consultation. Some earlier studies have concluded that early start of treatment had a positive effect on linear growth $(23,46)$. In one study however, the height $z$-score was generally higher in those who started treatment before the age of 1 year compared with those who started later, but declined over time for those who started treatment early and improved in those who started treatment later (46). We found that treatment with phosphate and vitamin D improved mineral homeostasis and rickets, but did not fully correct skeletal axis deviation and to a lesser extent correct the growth deficiency in HR. This adds support to the theory that FGF23 may play a role in the normal physiology of mineralized tissues independently phosphate regulation (18). Treatment with phosphate will lead to transient increases in serum phosphate, which trigger production and release of FGF23 (47) and PTH (48), further aggravating the skeletal phenotype. Novel therapy with FGF23 neutralizing antibodies has shown that inhibition of excess FGF23 activity correct growth deficiency in mice (49), and anti-FGF23 antibodies are currently being tested in human XLHR $(50,51)$. It is possible that longitudinal growth in $\mathrm{HH}$ patients reflects the individual severity of and response to a disturbed FGF23 homeostasis, rather than the severity of hypophosphatemia itself.

The patients who developed nephrocalcinosis had started treatment earlier and had received higher daily doses of phosphate, but did not have better growth outcomes, than patients without nephrocalcinosis. Renal function remained normal in all patients, except for transient low-grade renal failure seen in the XLHR patient with tertiary HPT. Our results strengthen the association between higher phosphate doses and development of nephrocalcinosis found in earlier studies $(52,53,54,55)$. Early start of treatment as a risk factor for nephrocalcinosis has been found by some $(52)$, but not by others $(23,46,56)$. The prevalence of nephrocalcinosis in patients receiving combination therapy with phosphate and calcitriol is reported to be from 33 to $80 \%$ (median 59\%) (23, 46, 52, $53,54,55,56,57,58)$, but long term follow-up of mild nephrocalcinosis in XLHR does not seem to affect renal function (56). As discussed above, treatment with phosphate and calcitriol has a certain positive effect on growth, but only phosphate-treated patients develop nephrocalcinosis $(54,55,56)$. This again probably reflects that current treatment options are suboptimal, both when considering skeletal outcome and the rate of complications.

Elevated serum levels of PTH were found in ten of 15 XLHR patients before the start of treatment all patients developed HPT during the course of treatment. Our findings add to other reports of high normal or slightly elevated levels of PTH in hypophosphatemic untreated XLHR patients $(59,60,61)$. In normal subjects, hypophosphatemia will, through an increase in $1,25(\mathrm{OH})_{2} \mathrm{D}$, reduce PTH levels (62). Evidence also suggests an inhibitory effect of FGF23 on PTH production (63). The explanation for the inappropriate PTH response in untreated HR, and the details of the interactions between phosphate, FGF23, and PTH, still need further clarification.

Secondary HPT caused by oral phosphate supplements can be counteracted by increasing the doses of calcitriol, with the risk of developing hypercalcuria and nephrocalcinosis, or by reducing the phosphate dose, with the risk of worsening rickets (64). However difficult, successful management of HPT in XLHR is important, as HPT has been associated with development of hypertension and renal failure $(24,65)$, cardiac failure (66), and also brown tumor in the mandible (67).

Two patients, one with XLHR, developed tertiary HPT after long-term use of phosphate supplements. The XLHR patient had received relatively high doses of phosphate and relatively low doses of alfacalcidol for more than 10 years. Tertiary HPT has been reported in 36 cases of HR $(24,65,66,68,69,70,71,72,73,74,75)$, and prolonged treatment with high doses of phosphate supplements seems to be a risk factor $(68,71)$. There are reports of successful treatment of tertiary HPT with cinacalcet in children $(24,76)$ and adults $(77,78)$, but safety concerns have stopped further clinical trials investigating the effects of cinacalcet in children (79). A recent report suggests the vitamin D analog paricalcitol to suppress elevated PTH secondary to treatment in XLHR (80). However, careful monitoring of treatment, to ensure lowest efficient phosphate dose is very important to heal rickets and at the same time reduce the risk of tertiary HPT.

The observations from this study support recently published guidelines on treatment and monitoring of HR in children $(64,81)$. We recommend that combined treatment with oral phosphate and activated vitamin D (calcitriol or alfacalcidol) is started once the diagnosis has been made. Most children respond well to a calcitriol dose of $20-30 \mathrm{ng} / \mathrm{kg}$ per day (divided in two doses) or alfacalcidol 30-50 ng/kg per day (single dose) and an elemental phosphorous dose of $20-40 \mathrm{mg} / \mathrm{kg}$ per day 
(divided in four doses) with reduced signs of rickets and skeletal deformities. The starting doses of phosphate should be kept low to reduce gastrointestinal side effects, and to avoid complications clinical and biochemical controls should be performed at least every 3 months, and supplemented with skeletal X-rays every 2 years and renal ultrasonography every $2-5$ years. To avoid HPT, the aim should not be normalization of serum phosphate, but the lowest efficient dose that promote growth and heal rickets. To minimize the risk of nephrocalcinosis, hypercalcuria, defined as $\mathrm{U}-\mathrm{Ca} /$ creatinine ratio $>0.87 \mathrm{mmol} /$ mmol should be avoided.

One strength of our study is related to the fact that combined data from the NPR and all pediatric centers in Norway allowed us to collect a complete national material of childhood HH. This allowed for the estimation of a national prevalence, and adds information to the literature on the epidemiology of hereditary HR. Moreover, we have identified new mutations in known and novel genes, expanding the genetic diversity of $\mathrm{HH}$ with and without rickets. On the other hand, the study is limited by the size of the cohort and the retrospective design, implying we could not ensure uniform collection of information from the clinical, biochemical, and radiological examinations. Furthermore, we did not do genetic testing on normophosphatemic, asymptomatic siblings, as predictive genetic testing on children is not allowed in Norway according to the Biotechnology Act. This means there is a possibility for undiagnosed subclinical cases.

In conclusion, we have presented the first complete national cohort of $\mathrm{HH}$ in children. The prevalence of XLHR seems to be lower in Norwegian children than reported earlier.

\section{Supplementary data}

This is linked to the online version of the paper at http://dx.doi.org/10.1530/ EJE-15-0515.

\section{Declaration of interest}

The authors declare that there is no conflict of interest that could be perceived as prejudicing the impartiality of the research reported.

Funding

This research was supported by a PhD grant from the University of Bergen.

Author contribution statement

S Rafaelsen, H Ræder, S Johansson, and R Bjerknes designed the study; S Rafaelsen collected the data; whereas S Rafaelsen, H Ræder, S Johansson, and R Bjerknes contributed to data analysis and interpretation. S Rafaelsen and $\mathrm{R}$ Bjerknes drafted the manuscript, whereas all authors contributed to the revision and approved the final version of the manuscript.

\section{Acknowledgements}

All patients and their families are thanked for making this study possible. We also thank the collaborating physicians Jon Bland at Stavanger University Hospital; Leif Brunvand, Anne Grethe Myhre, Kathrine Alsaker Heier, and Martin Heier at Oslo University Hospital; Torstein B Rø and Gunnhild Møllerløkken at St Olavs Hospital; Ketil Mevold, Dag Veimo, and Anne Kristine Fagerheim at Nordland County Hospital, Bodø; for recruiting patients. We thank the staff at the Laboratory of Centre of Medical Genetics and Molecular Medicine, Haukeland University Hospital, for expert technical support.

\section{References}

1 Carpenter TO. The expanding family of hypophosphatemic syndromes. Journal of Bone and Mineral Metabolism 201230 1-9. (doi:10.1007/ s00774-011-0340-2)

2 Shimada T, Hasegawa H, Yamazaki Y, Muto T, Hino R, Takeuchi Y, Fujita T, Nakahara K, Fukumoto S \& Yamashita T. FGF-23 is a potent regulator of vitamin $\mathrm{D}$ metabolism and phosphate homeostasis. Journal of Bone and Mineral Research 200419 429-435. (doi:10.1359/ JBMR.0301264)

3 Shimada T, Mizutani S, Muto T, Yoneya T, Hino R, Takeda S, Takeuchi Y, Fujita T, Fukumoto S \& Yamashita T. Cloning and characterization of FGF23 as a causative factor of tumor-induced osteomalacia. PNAS 200198 6500-6505. (doi:10.1073/pnas. 101545198)

4 Drezner MK, Lyles KW, Haussler MR \& Harrelson JM. Evaluation of a role for 1,25-dihydroxyvitamin D3 in the pathogenesis and treatment of X-linked hypophosphatemic rickets and osteomalacia. Journal of Clinical Investigation 198066 1020-1032. (doi:10.1172/JCI109930)

5 Francis F, Hennign S, Korn B, Reinhardt R, de Jong P, Poustka A, Lehrach H, Rowe PSN, Goulding JN, Summerfield T et al. A gene (PEX) with homologies to endopeptidases is mutated in patients with $\mathrm{X}$-linked hypophosphatemic rickets. The HYP Consortium. Nature Genetics 199511 130-136. (doi:10.1038/ng1095-130)

6 White KE, Evans WE, O'Riordan JLH, Speer MC, Econs MJ, Lorenz-Depiereux B, Grabowski M, Meitinger T \& Strom TM. Autosomal dominant hypophosphataemic rickets is associated with mutations in FGF23. Nature Genetics 200026 345-348. (doi:10.1038/81664)

7 Lorenz-Depiereux B, Bastepe M, Benet-Pages A, Amyere M, Wagenstaller J, Muller-Barth U, Badenhoop K, Kaiser SM, Rittmaster RS, Shlossberg AH et al. DMP1 mutations in autosomal recessive hypophosphatemia implicate a bone matrix protein in the regulation of phosphate homeostasis. Nature Genetics 200638 1248-1250. (doi:10.1038/ng1868)

8 Feng JQ, Ward LM, Liu S, Lu Y, Xie Y, Yuan B, Yu X, Rauch F, Davis SI, Zhang $\mathrm{S}$ et al. Loss of DMP1 causes rickets and osteomalacia and identifies a role for osteocytes in mineral metabolism. Nature Genetics 200638 1310-1315. (doi:10.1038/ng1905)

9 Levy-Litan V, Hershkovitz E, Avizov L, Leventhal N, Bercovich D, Chalifa-Caspi V, Manor E, Buriakovsky S, Hadad Y, Goding J et al. Autosomal-recessive hypophosphatemic rickets is associated with an inactivation mutation in the ENPP1 gene. American Journal of Human Genetics 201086 273-278. (doi:10.1016/j.ajhg.2010.01.010)

10 Lorenz-Depiereux B, Schnabel D, Tiosano D, Hausler G \& Strom TM. Loss-of-function ENPP1 mutations cause both generalized arterial calcification of infancy and autosomal-recessive hypophosphatemic 
rickets. American Journal of Human Genetics 201086 267-272. (doi:10.1016/j.ajhg.2010.01.006)

11 Rafaelsen SH, Raeder H, Fagerheim AK, Knappskog P, Carpenter TO, Johansson S \& Bjerknes R. Exome sequencing reveals FAM20c mutations associated with fibroblast growth factor 23-related hypophosphatemia, dental anomalies, and ectopic calcification. Journal of Bone and Mineral Research 201328 1378-1385. (doi:10.1002/ jbmr.1850)

12 Tagliabracci VS, Engel JL, Wiley SE, Xiao J, Gonzalez DJ, Nidumanda Appaiah H, Koller A, Nizet V, White KE \& Dixon JE. Dynamic regulation of FGF23 by Fam20C phosphorylation, GalNAc-T3 glycosylation, and furin proteolysis. PNAS $20141115520-5525$. (doi:10.1073/pnas.1402218111)

13 Wang X, Wang S, Li C, Gao T, Liu Y, Rangiani A, Sun Y, Hao J, George A, $\mathrm{Lu} \mathrm{Y}$ et al. Inactivation of a novel FGF23 regulator, FAM20C, leads to hypophosphatemic rickets in mice. PLoS Genetics 20128 e1002708. (doi:10.1371/journal.pgen.1002708)

14 Brownstein CA, Adler F, Nelson-Williams C, Iijima J, Li P, Imura A, Nabeshima Y, Reyes-Mugica M, Carpenter TO \& Lifton RP. A translocation causing increased $\alpha$-klotho level results in hypophosphatemic rickets and hyperparathyroidism. PNAS 2008105 3455-3460. (doi:10.1073/pnas.0712361105)

15 Bergwitz C, Roslin NM, Tieder M, Loredo-Osti JC, Bastepe M, Abu-Zahra H, Frappier D, Burkett K, Carpenter TO, Anderson D et al. SLC34A3 mutations in patients with hereditary hypophosphatemic rickets with hypercalciuria predict a key role for the sodium-phosphate cotransporter NaPi-IIc in maintaining phosphate homeostasis. American Journal of Human Genetics 200678 179-192. (doi:10.1086/499409)

16 Lorenz-Depiereux B, Benet-Pages A, Eckstein G, Tenenbaum-Rakover Y, Wagenstaller J, Tiosano D, Gershoni-Baruch R, Albers N, Lichtner P, Schnabel D et al. Hereditary hypophosphatemic rickets with hypercalciuria is caused by mutations in the sodium-phosphate cotransporter gene SLC34A3. American Journal of Human Genetics 200678 193-201. (doi:10.1086/499410)

17 Glorieux FH, Scriver CR, Reade TM, Goldman H \& Roseborough A. Use of phosphate and vitamin D to prevent dwarfism and rickets in X-linked hypophosphatemia. New England Journal of Medicine 1972287 481-487. (doi:10.1056/NEJM197209072871003)

18 Linglart A, Biosse-Duplan M, Briot K, Chaussain C, Esterle L, Guillaume-Czitrom S, Kamenicky P, Nevoux J, Prie D, Rothenbuhler A et al. Therapeutic management of hypophosphatemic rickets from infancy to adulthood. Endocrine Connections 20143 R13-R30. (doi:10.1530/EC-13-0103)

19 Juliusson PB, Roelants M, Nordal E, Furevik L, Eide GE, Moster D, Hauspie R \& Bjerknes R. Growth references for 0-19 year-old Norwegian children for length/height, weight, body mass index and head circumference. Annals of Human Biology 201340 220-227. (doi:10.3109/03014460.2012.759276)

20 Barth JH, Jones RG \& Payne RB. Calculation of renal tubular reabsorption of phosphate: the algorithm performs better than the nomogram. Annals of Clinical Biochemistry 200037 79-81. (doi:10.1258/0004563001901371)

21 Morey M, Castro-Feijoo L, Barreiro J, Cabanas P, Pombo M, Gil M, Bernabeu I, Diaz-Grande JM, Rey-Cordo L, Ariceta G et al. Genetic diagnosis of X-linked dominant hypophosphatemic rickets in a cohort study: tubular reabsorption of phosphate and $1,25(\mathrm{OH})_{2} \mathrm{D}$ serum levels are associated with PHEX mutation type. BMC Medical Genetics 201112 116. (doi:10.1186/1471-2350-12-116)

22 Statistics Norway. (https://www.ssb.no/statistikkbanken/ selectout/ShowTable.asp?FileformatId $=2 \&$ Queryfile $=$ 20151120125141735872111 NY3026\&PLanguage $=0 \&$ MainTable $=$ NY3026\&potsize $=36$ Accession date Nov.4th 2015)

23 Makitie O, Doria A, Kooh SW, Cole WG, Daneman A \& Sochett E. Early treatment improves growth and biochemical and radiographic outcome in X-linked hypophosphatemic rickets. Journal of Clinical
Endocrinology and Metabolism 200388 3591-3597. (doi:10.1210/jc. 2003-030036)

24 Raeder H, Shaw N, Netelenbos C \& Bjerknes R. A case of X-linked hypophosphatemic rickets: complications and the therapeutic use of cinacalcet. European Journal of Endocrinology 2008159 (Suppl 1) S101-S105. (doi:10.1530/EJE-08-0383)

25 Davies M \& Stanbury SW. The rheumatic manifestations of metabolic bone-disease. Clinics in Rheumatic Diseases 19817 595-646.

26 Beck-Nielsen SS, Brock-Jacobsen B, Gram J, Brixen K \& Jensen TK. Incidence and prevalence of nutritional and hereditary rickets in southern Denmark. European Journal of Endocrinology 2009160 491-497. (doi:10.1530/EJE-08-0818)

27 Graham JB, Mc FV \& Winters RW. Familial hypophosphatemia with vitamin D-resistant rickets. II: three additional kindreds of the sexlinked dominant type with a genetic analysis of four such families. American Journal of Human Genetics 195911 311-332.

28 Gaucher C, Walrant-Debray O, Nguyen TM, Esterle L, Garabedian M \& Jehan F. PHEX analysis in 118 pedigrees reveals new genetic clues in hypophosphatemic rickets. Human Genetics 2009125 401-411. (doi:10.1007/s00439-009-0631-z)

29 Beck-Nielsen SS, Brixen K, Gram J \& Brusgaard K. Mutational analysis of PHEX, FGF23, DMP1, SLC34A3 and CLCN5 in patients with hypophosphatemic rickets. Journal of Human Genetics 201257 453-458. (doi:10.1038/jhg.2012.56)

30 Abe Y, Nagasaki K, Watanabe T, Abe T \& Fukami M. Association between compound heterozygous mutations of SLC34A3 and hypercalciuria. Hormone Research in Paediatrics 201482 65-71. (doi:10.1159/000360291)

31 Dasgupta D, Wee MJ, Reyes M, Li Y, Simm PJ, Sharma A, Schlingmann KP, Janner M, Biggin A, Lazier J et al. Mutations in SLC34A3/NPT2c are associated with kidney stones and nephrocalcinosis. Journal of the American Society of Nephrology 201425 2366-2375. (doi:10.1681/ASN.2013101085)

32 Rowe PS, Oudet CL, Francis F, Sinding C, Pannetier S, Econs MJ, Strom TM, Meitinger T, Garabedian M, David A et al. Distribution of mutations in the PEX gene in families with X-linked hypophosphataemic rickets (HYP). Human Molecular Genetics 19976 539-549. (doi:10.1093/hmg/6.4.539)

33 Song HR, Park JW, Cho DY, Yang JH, Yoon HR \& Jung SC. PHEX gene mutations and genotype-phenotype analysis of Korean patients with hypophosphatemic rickets. Journal of Korean Medical Science 200722 981-986. (doi:10.3346/jkms.2007.22.6.981)

34 Cho HY, Lee BH, Kang JH, Ha IS, Cheong HI \& Choi Y. A clinical and molecular genetic study of hypophosphatemic rickets in children. Pediatric Research 200558 329-333. (doi:10.1203/01.PDR.0000169983. 40758.7B)

35 Holm IA, Nelson AE, Robinson BG, Mason RS, Marsh DJ, Cowell CT \& Carpenter TO. Mutational analysis and genotype-phenotype correlation of the PHEX gene in X-linked hypophosphatemic rickets. Journal of Clinical Endocrinology and Metabolism 200186 3889-3899. (doi:10.1210/jcem.86.8.7761)

36 Econs MJ, Friedman NE, Rowe PS, Speer MC, Francis F, Strom TM, Oudet C, Smith JA, Ninomiya JT, Lee BE et al. A PHEX gene mutation is responsible for adult-onset vitamin D-resistant hypophosphatemic osteomalacia: evidence that the disorder is not a distinct entity from X-linked hypophosphatemic rickets. Journal of Clinical Endocrinology and Metabolism 199883 3459-3462. (doi:10.1210/jcem.83.10.5167)

37 Rendina D, Esposito T, Mossetti G, De Filippo G, Gianfrancesco F, Perfetti A, Magliocca S, Formisano P, Prie D \& Strazzullo P. A functional allelic variant of the FGF23 gene is associated with renal phosphate leak in calcium nephrolithiasis. Journal of Clinical Endocrinology and Metabolism 201297 E840-E844. (doi:10.1210/jc.2011-1528)

38 Pekkinen M, Laine CM, Makitie R, Leinonen E, Lamberg-Allardt C, Viljakainen $\mathrm{H} \&$ Makitie O. FGF23 gene variation and its association with phosphate homeostasis and bone mineral density in Finnish 
children and adolescents. Bone 201571 124-130. (doi:10.1016/j.bone. 2014.10.013)

39 Burnett CH, Dent CE, Harper C \& Warland BJ. Vitamin D-resistant rickets. Analysis of twenty-four pedigrees with hereditary and sporadic cases. American Journal of Medicine 196436 222-232. (doi:10.1016/ 0002-9343(64)90085-3)

40 Reid IR, Hardy DC, Murphy WA, Teitelbaum SL, Bergfeld MA \& Whyte MP. X-linked hypophosphatemia: a clinical, biochemical, and histopathologic assessment of morbidity in adults. Medicine 198968 336-352. (doi:10.1097/00005792-198911000-00002)

41 Winters RW, Mc FV \& Graham JB. Genetic studies of vitamin D resistant rickets and familial hypophosphatemia. Helvetica Paediatrica Acta 1959 14 533-538.

42 Hardy DC, Murphy WA, Siegel BA, Reid IR \& Whyte MP. X-linked hypophosphatemia in adults: prevalence of skeletal radiographic and scintigraphic features. Radiology 1989171 403-414. (doi:10.1148/ radiology.171.2.2539609)

43 Whyte MP, Schranck FW \& Armamento-Villareal R. X-linked hypophosphatemia: a search for gender, race, anticipation, or parent of origin effects on disease expression in children. Journal of Clinical Endocrinology and Metabolism 199681 4075-4080. (doi:10.1210/jcem. 81.11.8923863)

44 Shields ED, Scriver CR, Reade T, Fujiwara TM, Morgan K, Ciampi A \& Schwartz S. X-linked hypophosphatemia: the mutant gene is expressed in teeth as well as in kidney. American Journal of Human Genetics 199046 $434-442$.

45 Chaussain-Miller C, Sinding C, Wolikow M, Lasfargues JJ, Godeau G \& Garabedian M. Dental abnormalities in patients with familial hypophosphatemic vitamin D-resistant rickets: prevention by early treatment with 1-hydroxyvitamin D. Journal of Pediatrics $2003 \mathbf{1 4 2}$ 324-331. (doi:10.1067/mpd.2003.119)

46 Quinlan C, Guegan K, Offiah A, Neill RO, Hiorns MP, Ellard S, Bockenhauer D, Hoff WV \& Waters AM. Growth in PHEX-associated $\mathrm{X}$-linked hypophosphatemic rickets: the importance of early treatment. Pediatric Nephrology 201227 581-588. (doi:10.1007/s00467011-2046-z)

47 Imel EA, DiMeglio LA, Hui SL, Carpenter TO \& Econs MJ. Treatment of $\mathrm{X}$-linked hypophosphatemia with calcitriol and phosphate increases circulating fibroblast growth factor 23 concentrations. Journal of Clinical Endocrinology and Metabolism 201095 1846-1850. (doi:10.1210/ jc.2009-1671)

48 Reiss E, Canterbury JM, Bercovitz MA \& Kaplan EL. The role of phosphate in the secretion of parathyroid hormone in man. Journal of Clinical Investigation 197049 2146-2149. (doi:10.1172/JCI106432)

49 Aono Y, Yamazaki Y, Yasutake J, Kawata T, Hasegawa H, Urakawa I, Fujita T, Wada M, Yamashita T, Fukumoto $S$ et al. Therapeutic effects of anti-FGF23 antibodies in hypophosphatemic rickets/osteomalacia. Journal of Bone and Mineral Research 200924 1879-1888. (doi:10.1359/ jbmr.090509)

50 Carpenter TO, Imel EA, Ruppe MD, Weber TJ, Klausner MA, Wooddell MM, Kawakami T, Ito T, Zhang X, Humphrey J et al. Randomized trial of the anti-FGF23 antibody KRN23 in X-linked hypophosphatemia. Journal of Clinical Investigation 2014124 1587-1597. (doi:10.1172/JCI72829)

51 Imel EA, Zhang X, Ruppe MD, Weber TJ, Klausner MA, Ito T, Vergeire M, Humphrey JS, Glorieux FH, Portale AA et al. Prolonged correction of serum phosphorus in adults with X-linked hypophosphatemia using monthly doses of KRN23. Journal of Clinical Endocrinology and Metabolism 2015100 2565-2573. (doi:10.1210/jc. 2015-1551)

52 Goodyer PR, Kronick JB, Jequier S, Reade TM \& Scriver CR. Nephrocalcinosis and its relationship to treatment of hereditary rickets. Journal of Pediatrics 1987111 700-704. (doi:10.1016/S0022-3476 (87)80245-7)

53 Reusz GS, Hoyer PF, Lucas M, Krohn HP, Ehrich JH \& Brodehl J. X linked hypophosphataemia: treatment, height gain, and nephrocalcinosis.
Archives of Disease in Childhood 199065 1125-1128. (doi:10.1136/adc. 65.10.1125)

54 Taylor A, Sherman NH \& Norman ME. Nephrocalcinosis in X-linked hypophosphatemia: effect of treatment versus disease. Pediatric Nephrology 19959 173-175. (doi:10.1007/BF00860736)

55 Verge CF, Lam A, Simpson JM, Cowell CT, Howard NJ \& Silink M. Effects of therapy in X-linked hypophosphatemic rickets. New England Journal of Medicine 1991325 1843-1848. (doi:10.1056/ NEJM199112263252604)

56 Kooh SW, Binet A \& Daneman A. Nephrocalcinosis in X-linked hypophosphataemic rickets: its relationship to treatment, kidney function, and growth. Clinical and Investigative Medicine. Médecine Clinique et Experimentale 199417 123-130.

57 Alon U, Donaldson DL, Hellerstein S, Warady BA \& Harris DJ. Metabolic and histologic investigation of the nature of nephrocalcinosis in children with hypophosphatemic rickets and in the Hyp mouse. Journal of Pediatrics 1992120 899-905. (doi:10.1016/S0022-3476 (05)81957-2)

58 Patzer L, van't Hoff W, Shah V, Hallson P, Kasidas GP, Samuell C, de Bruyn R, Barratt TM \& Dillon MJ. Urinary supersaturation of calcium oxalate and phosphate in patients with X-linked hypophosphatemic rickets and in healthy schoolchildren. Journal of Pediatrics 1999135 611-617. (doi:10.1016/S0022-3476(99)70060-0)

59 Carpenter TO, Mitnick MA, Ellison A, Smith C \& Insogna KL. Nocturnal hyperparathyroidism: a frequent feature of X-linked hypophosphatemia. Journal of Clinical Endocrinology and Metabolism 199478 1378-1383. (doi:10.1210/jcem.78.6.8200940)

60 Rasmussen H, Pechet M, Anast C, Mazur A, Gertner J \& Broadus AE. Long-term treatment of familial hypophosphatemic rickets with oral phosphate and $1 \alpha$-hydroxyvitamin D3. Journal of Pediatrics 198199 16-25. (doi:10.1016/S0022-3476(81)80951-1)

61 Lewy JE, Cabana EC, Repetto HA, Canterbury JM \& Reiss E. Serum parathyroid hormone in hypophosphatemic vitamin D-resistant rickets. Journal of Pediatrics $1972 \mathbf{8 1}$ 294-300. (doi:10.1016/S00223476(72)80298-1)

62 Lanske B \& Razzaque MS. Molecular interactions of FGF23 and PTH in phosphate regulation. Kidney International 201486 1072-1074. (doi:10.1038/ki.2014.316)

63 Krajisnik T, Bjorklund P, Marsell R, Ljunggren O, Akerstrom G, Jonsson KB, Westin G \& Larsson TE. Fibroblast growth factor-23 regulates parathyroid hormone and $1 \alpha$-hydroxylase expression in cultured bovine parathyroid cells. Journal of Endocrinology 2007195 125-131. (doi:10.1677/JOE-07-0267)

64 Carpenter TO, Imel EA, Holm IA, Jan de Beur SM \& Insogna KL. A clinician's guide to X-linked hypophosphatemia. Journal of Bone and Mineral Research 201126 1381-1388. (doi:10.1002/jbmr.340)

65 Alon US, Monzavi R, Lilien M, Rasoulpour M, Geffner ME \& Yadin O. Hypertension in hypophosphatemic rickets - role of secondary hyperparathyroidism. Pediatric Nephrology 200318 155-158. (doi:10.1007/s00467-002-1044-6)

66 Sun GE, Suer O, Carpenter TO, Tan CD \& Li-Ng M. Heart failure in hypophosphatemic rickets: complications from high-dose phosphate therapy. Endocrine Practice 201319 e8-e11. (doi:10.4158/EP12184.CR)

67 Andrews RG, Baumhardt H, Martin B, Belachew D \& Reyes-Mugica M. Oral manifestations of hyperparathyroidism secondary to familial hypophosphatemic rickets. Pediatric Dentistry 201436 422-424.

68 Makitie O, Kooh SW \& Sochett E. Prolonged high-dose phosphate treatment: a risk factor for tertiary hyperparathyroidism in X-linked hypophosphatemic rickets. Clinical Endocrinology 200358 163-168. (doi:10.1046/j.1365-2265.2003.01685.x)

69 Tournis S, Georgoulas T, Zafeiris C, Papalexis C, Petraki K \& Lyritis GP. Tertiary hyperparathyroidism in a patient with X-linked hypophosphatemic rickets. Journal of Musculoskeletal \& Neuronal Interactions 2011 $11266-269$.

70 Neal MD, Deslouches B \& Ogilvie J. The use of pre-operative imaging and intraoperative parathyroid hormone level to guide surgical 
management of tertiary hyperparathyroidism from X-linked hypophosphatemic rickets: a case report. Cases Journal 200927572. (doi:10.4076/1757-1626-2-7572)

71 McHenry CR, Mostafavi K \& Murphy TA. Tertiary hyperparathyroidism attributable to long-term oral phosphate therapy. Endocrine Practice 200612 294-298. (doi:10.4158/EP.12.3.294)

72 Savio RM, Gosnell JE, Posen S, Reeve TS \& Delbridge LW. Parathyroidectomy for tertiary hyperparathyroidism associated with X-linked dominant hypophosphatemic rickets. Archives of Surgery 2004139 218-222. (doi:10.1001/archsurg.139.2.218)

$73 \mathrm{Wu}$ CJ, Song YM \& Sheu WH. Tertiary hyperparathyroidism in X-linked hypophosphatemic rickets. Internal Medicine 200039 468-471. (doi:10. 2169/internalmedicine.39.468)

74 Moreno Molina JA, Lopez Siguero JP, Bueno Fernandez A, MartinezAedo Ollero MJ \& Martinez Valverde A. Tertiary hyperparathyroidism during the treatment of familial hypophosphatemic rickets. Anales Españoles de Pediatría 199645 193-195.

75 Knudtzon J, Halse J, Monn E, Nesland A, Nordal KP, Paus P, Seip M, Sund S \& Sodal G. Autonomous hyperparathyroidism in X-linked hypophosphataemia. Clinical Endocrinology 199542 199-203. (doi:10. 1111/j.1365-2265.1995.tb01863.x)

76 Alon US, Levy-Olomucki R, Moore WV, Stubbs J, Liu S \& Quarles LD. Calcimimetics as an adjuvant treatment for familial hypophosphatemic rickets. Clinical Journal of the American Society of Nephrology 20083 658-664. (doi:10.2215/CJN.04981107)

77 Grove-Laugesen D \& Rejnmark L. Three-year successful cinacalcet treatment of secondary hyperparathyroidism in a patient with X-linked dominant hypophosphatemic rickets: a case report. Case Reports in Endocrinology 20142014 479641. (doi:10.1155/2014/479641)

78 Yavropoulou MP, Kotsa K, Gotzamani Psarrakou A, Papazisi A, Tranga T, Ventis S \& Yovos JG. Cinacalcet in hyperparathyroidism secondary to X-linked hypophosphatemic rickets: case report and brief literature review. Hormones 20109 274-278. (doi:10.14310/horm.2002. 1277)

79 US Food and Drug Administration. Sensipar (cinacalcet hydrochloride): drug safety communication. FDA suspends pediatric clinical trials after report of death: US Food and Drug Administration, 2013. (http://www. fda.gov/Safety/MedWatch/SafetyInformation/SafetyAlertsforHuman MedicalProducts/ucm341255.htm Accession date Nov.4th 2015)

80 Carpenter TO, Olear EA, Zhang JH, Ellis BK, Simpson CA, Cheng D, Gundberg CM \& Insogna KL. Effect of paricalcitol on circulating parathyroid hormone in X-linked hypophosphatemia: a randomized, double-blind, placebo-controlled study. Journal of Clinical Endocrinology and Metabolism 201499 3103-3111. (doi:10.1210/jc.2014-2017)

81 Imel EA \& Carpenter TO. A practical clinical approach to paediatric phosphate disorders. Endocrine Development 201528 134-161. (doi:10.1159/000381036)

Received 24 May 2015

Revised version received 2 October 2015

Accepted 4 November 2015 